\title{
Using cognitive work analysis to develop predictive maintenance tool for vessels
}

\author{
Loïck Simon, Clément Guérin, Philippe Rauffet and Julie Lassalle \\ Lab-STICC CNRS UMR 6285, University of South Brittany, France. \\ E-mail: loick.simon@univ-ubs.fr ; clement.guerin@univ-ubs.fr ; philippe.rauffet@univ-ubs.fr ; julie.lassalle@univ-ubs.fr
}

\begin{abstract}
Implementation of multisource sensors combined with data analysis systems (e.g. machine learning) might provide new solutions for predictive maintenance to improve sociotechnical system reliability. The Seanatic project aims to develop a decision support tool to increase maintenance processes in the maritime field, considering limits and benefits of human factor expertise. Under this perspective, this paper describes the Cognitive Work Analysis (CWA) approach for investigating new key functions that emerge in future maintenance sociotechnical systems. After phase one of the CWA was completed (WDA Work Domain Analysis), the functions identified were used in the subsequent phases (ConTA - Control Task Analysis and SOCA - Social Organization and Cooperation Analysis) to highlight different implications for human cognitive activities. Realtime and prediction of machine breakdown of a vessel could be significantly reduced by assisting the chief engineer for supervision and planning activities. Based on a CWA approach, ecological design interfaces could support those activities.
\end{abstract}

Keywords: Cognitive Work Analysis, Control Task Analysis, Ecological Interface Design, Maritime Maintenance, Social Organization \& Cooperation Analysis, Predictive Maintenance, Work Domain Analysis,

\section{Introduction}

Multiplication of data from sensors on equipment offers increased capabilities for companies (Culot, Nassimbeni, Orzes \& Sartor, 2020). Combined with techniques from data mining or machine learning, new systems allow enhanced capabilities in monitoring, modeling, analysis, and calculations (Longo et al., 2017). These technological developments contribute to changing maintenance practices and evolving towards predictive maintenance (Yan, Meng, Lu \& Lee, 2017 ; Wan \& al, 2017 ; Yang, Yang, Yang \& Chen, 2020). Maintenance can be categorized into different types, according to NF-EN 13306:V2018. Corrective maintenance (which is carried out after failure detection) is distinguished from preventive maintenance (the equipment is still working). Furthermore, this proactive maintenance strategy can be divided into systematic (timestamp data-based, without controlling equipment' state), condition-based (key parameters are controlled such as temperature), and predictive (using historical data of parameters such as viscosity curve in order to identify unusual patterns). Development of predictive maintenance strategies (or maintenance 4.0) is the next logical step for companies, after preventive condition-based maintenance (Lazakis \& Ölçer, 2016). Thanks to predictive analysis based on repeated observations and measurements, maintenance teams can now be aware of accurate states of the machines. Finally, maintenance 4.0 offers great opportunities to reduce costs and environmental impact, this latter challenge being a normative requirement of the NF-EN 13306:V2018 standard.

The present communication deals with the ongoing project called Seanatic. The aim of this project is to implement predictive maintenance in the maritime sector. The bulk of maintenance is preventive systematic and condition-based maintenance. For systematic maintenance, CMMS (Computerized maintenance management system) tools integrate manufacturers' recommendations in terms of usage time (e.g., change equipment after 10,000 hours of use) or calendar dates (e.g. every 18 months). Conditionbased maintenance relies on human observations of physical values (there may be some sensors). Costs of maintenance derive from inventory materials (Tinga, Tiddens, Amoiralis \& Politis, 2017). Turan, Ölçer, Lazakis, Rigo and Caprace (2009) indicate that expenses related to maintenance for tankers would be between 25 and $35 \%$ of global operating costs. Studies in the maritime domain have shown the benefit of preventive maintenance compared with corrective (Goossens \& Basten, 2015; Eruguz, Tan, \& van Houtum, 2017). In a survey among the experts (technical manager of a maritime company, chief engineer, second engineer, engineer officer), Lazakis and Ölçer (2016) pointed out that predictive maintenance would be the most appropriate for vessels. The most advance maintenance used actually is the conditional maintenance and is focused on unique data (e.g., tightness or level of battery). Only a few collect and process multiple data from sensors (e.g., temperature probes, pressure sensors). Data are processed and analyzed off the ship in order to postpone maintenance operations. Ship classification societies, which certify that the construction and the maintenance of a vessel complies with relevant standards, have agreed to integrate these solutions in the maritime domain.

The Seanatic project aims to develop a decision support tool for predictive maintenance. From a human factor perspective, this paper describes the Cognitive

Proceedings of the 31th European Safety and Reliability Conference

Edited by Bruno Castanier, Marko Cepin, David Bigaud and Christophe Berenguer

Copyright $@ 2021$ by ESREL2021 Organizers. Published by Research Publishing, Singapore

ISBN: 981-973-0000-00-0 :: doi: 10.3850/981-973-0000-00-0 esrel2021-paper 


\section{Loïck Simon, Clément Guérin, Philippe Rauffet and Julie Lassalle}

Work Analysis approach to analyze the maintenance system in a maritime environment. The objective is to identify new key functions and their implication for cognitive human activities. This methodology is used to develop ecological interfaces for supporting human decision making.

\section{Method: Cognitive Work Analysis}

For Holman et al. (2020) Cognitive Work Analysis (CWA) is an appropriate method to analyze sociotechnical systems. There are three main characteristics of these systems (Walker, Stanton, Salmon, Jenkins and Rafferty, 2010) that can be applied to the field of maintenance:

- Dynamism: the system can change state over time without human or autonomous agent intervention. For maintenance system, many physical components (e.g., propulsion, air conditioning, electrical devices) may have to change their condition without external intervention

- Uncertainty: it is complex to know all the components of the system and their changes over time. For the maintenance system, it is complicated to know the states of all the components of the system because of their large number and their poor accessibility.

- Multiplicity: a multitude of causes can lead to the same problem. For maritime maintenance system, there are many ways to lose the engine of the ship (e.g., piston breaking, fuel leak)

CWA is a framework developed for the design of complex sociotechnical systems (Rasmussen, 1986). CWA is a formative constraint-based approach. Unlike the descriptive approach (which describes how tasks are performed) and the normative approach (which indicates how tasks should be performed), the formative approach identifies the constraints determining the tasks and the limits of the work environment (Raymond, Prun \& Cegarra, 2016). The CWA method consists of five successive stages (Rauffet, Chauvin, Morel \& Berruet, 2015): a) Work Domain Analysis (WDA), b) Control Task Analysis (ConTA), c) Strategies Analysis (StrA), d) Social Organization and Cooperation Analysis (SOCA), and e) Worker Competencies Analysis (WCA). In this paper, we present the three phases developed in the Seanatic project: WDA, ConTA and SOCA.

Work Domain Analysis allows to define the functions of the work domain but also the physical objects that can provide data. WDA helps to understand the physical or social constraints of the work environment. WDA is associated with a modelling tool, the Abstraction Hierarchy (AH) The $\mathrm{AH}$ reflects the main objectives of the system ("functional purpose") and what leads to it and what is necessary to take into account ("values and priority measures"). The AH also reflects the main functions which contribute to the functional purpose ("purpose- related function") and the physical object used in these activities ("object-related process" and "physical object"). Control Task Analysis is related to the activity required for achieving a system's purpose. ConTA enables us to understand tasks carried out by agents (human operators or machines) of the system. ConTA is associated with a modelling tool, the Contextual Activity Template (CAT). The CAT uses the "purpose-related functions" and the object-related processes" to highlight how they are used in a specific situation or for an activity. Social Organization and Cooperation Analysis addresses the constraints governing the distribution of work and cooperation amongst the different agents. Jenkins et al. (2010) propose to map agents with a color code onto the CAT (SOCA-CAT).

CWA is based on data gathering techniques (Jenkins et al., 2008). For the Seanatic project, we used document review, interviews and expert review in the maritime domain. The main documents are NF-EN 13306:V2018 standard and the technical documentation of Kongsberg simulator (Engine Room MAN B\&W 5L90MC - L11). Two modes of interview were conducted: open-ended and semi-structured. Three themes were carried out during semi-structured interviews (maintenance work, integration of predictive maintenance, user requirements for a decision support tool for predictive maintenance). These interviews took between an hour and an hour and a half. Five former chief engineers participated (Age $\mathrm{M}=50 \mathrm{y}, \mathrm{SD}=9 \mathrm{y}$; Navigation experience $\mathrm{M}=$ $19 \mathrm{y}, \mathrm{SD}=15 \mathrm{y})$.

\section{Results}

There has been little attention on maritime maintenance systems using CWA. To our knowledge, only the study of Torenvliet, Jamieson and Cournoyer (2006) used this methodological framework to analyze damage management on ships. The authors sought to better understand what happens before and after damage occurrence using domain analysis (WDA stage of CWA) but their research spectrum was not how maintenance was done on day-to-day.

\subsection{WDA}

The work domain analysis was carried out from the point of view of the maintenance teams, more particularly the chief engineer. The main objective was to have a better understanding of the integration of predictive maintenance in the current work activities and relationship with condition-based preventive maintenance. The analysis is limited to the merchant navy. Merchant marine vessels are diverse (from small passenger ships to supertankers) and this diversity is considered in the analysis by adopting a generalist vision. Due to the health situation, vessels can't receive visitors therefore we couldn't visit it.

The integration of predictive maintenance into the maintenance system highlights two new functional 


\section{Lö̈ck Simon, Clément Guérin, Philippe Rauffet and Julie Lassalle}

purposes ("optimization of equipment knowledge" and "optimization of CMMS") (blue items) (Fig. 1). The integration of predictive maintenance will also impact the red items. There are three functional purposes in maritime maintenance and they are interconnected. The vessel's safety is directly related to the authorization and the vessel optimal condition. Value and priority measures are particularly linked to compliance with legislation ("Adapted management of critical elements", "Respect or modification of CMMS"). The two main purpose related functions have been identified: supervised activity ("Know the condition of the equipment", "Monitor energy consumption", "Assess future failures", "Take into account contextual elements") and planning or replanning of the maintenance schedule ("Follow
CMMS instructions", "Readjust the CMMS schedule", "Plan maintenance interventions"). The knowledge of the equipment condition is an important aspect of the work domain. Knowledge of the context is also an important aspect of the work domain because it will allow the operator to infer the equipment condition. Concerning the object-related processes, visualization is one of the main processes (visualization of control measure, visualization of energy consumption, historization and visualization of contextual information). Maintenance uses different types of tools. Some are technological ("exterior sensors", "camera", "CMMS"), some are biological ("nose or eyes") and some might be considered as databases ("manufacturer information", "passage planning").

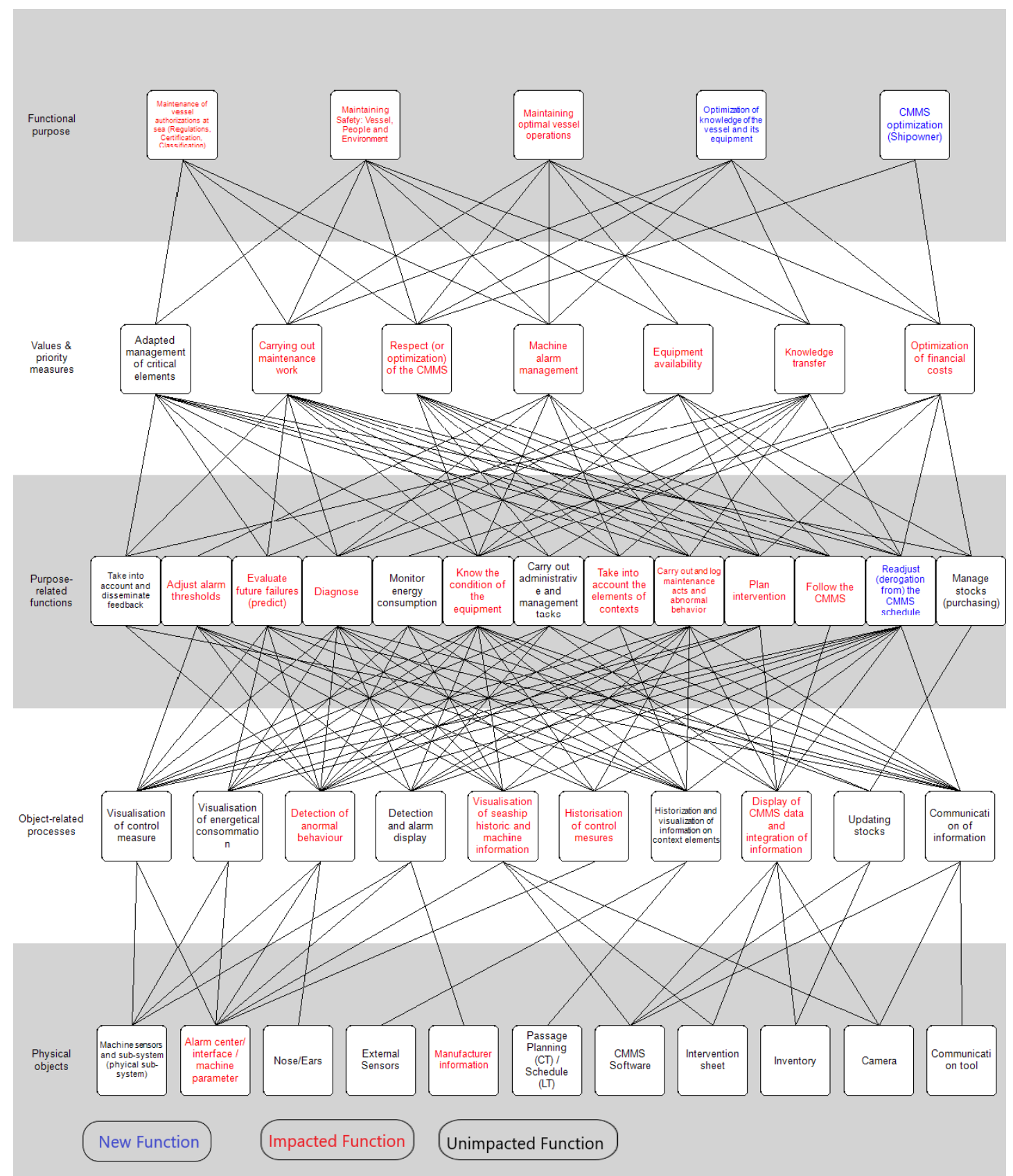

Figure 1: Abstraction Hierarchy for Predictive maintenance in maritime domain 


\section{Lö̈ck Simon, Clément Guérin, Philippe Rauffet and Julie Lassalle}

\subsection{SOCA-CAT}

It's important to remember that the crew size differs between the vessels. Some vessels will have only two-member crew (one chief engineer and one technician maintenance) when other vessels will have a larger crew member (one chief, one second, two or more officers and two or more technicians). This SOCA-CAT (Fig. 2) is used in a situation where the crew consisted of more than 5 members. This SOCA-CAT only includes the functions that will be impacted by predictive maintenance.

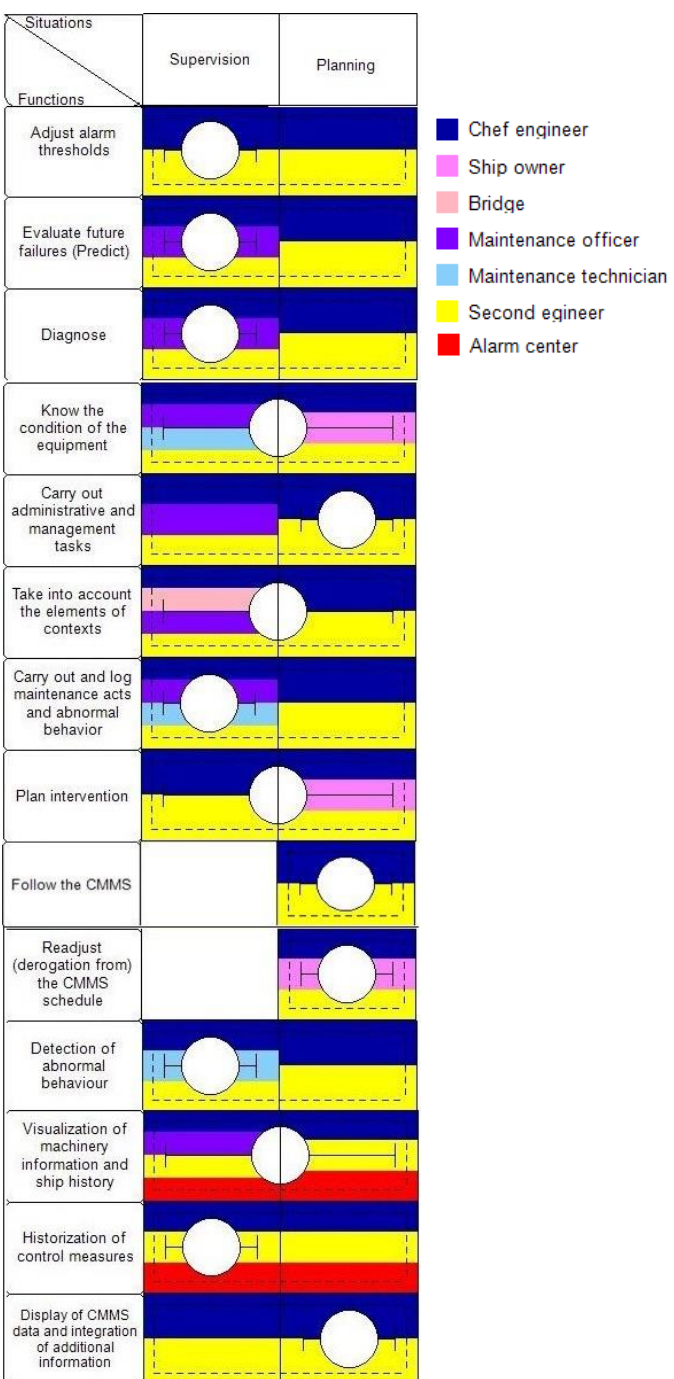

Figure 2: SOCA-CAT (supervision and planning)

With a reduced crew the chief engineer will assume multiple roles. As a reminder, when the cell is empty it means that the function never occurs in this situation. If the box is filled with a box and whisker plot, then the function is very often used. When the function might be used in this situation, but not every time, then the cell will have a dash outline. This SOCA-CAT highlights two things. The first one is that re-planning will need less functionality than the supervision. Re-planning will mainly use the function "Follow the CMMS" and the function "Know the condition of the equipment". The second one is that the chief engineer and his second are in charge of a lot of functions for supervision and re-planning. They are in charge of the planning of the interventions and then dispatch it to the other crewmate. We can see that the alarm center plays a major role because it will display the alarm. Alarms help with the major function of "know the condition of the equipment". The supervision activity is in close relation with the alarm center because it is the main tool which it uses to have access to the equipment's information. Taking into account the contextual elements is a crucial function of supervision and re-planning activity. It will allow engineers to understand any abnormal behavior (in the supervision) and it will allow to re-plan some maintenance by, for example, taking into account the "Passage Planning " of the vessel or the weather.

For a better understanding of the re-planning activity we have created a separate CAT (Fig. 3). This CAT associates the function of re-planning that will be impacted by predictive maintenance with different time of navigation. We can see that the activity of re-planning exclusively takes place during calm periods ("technical stop" and "calm sea"). Therefore, this activity is only performed when there is no time pressure and contextual constraint for the operator. Another CAT has also been made for the supervision activity and shows that this activity takes place in all contexts.

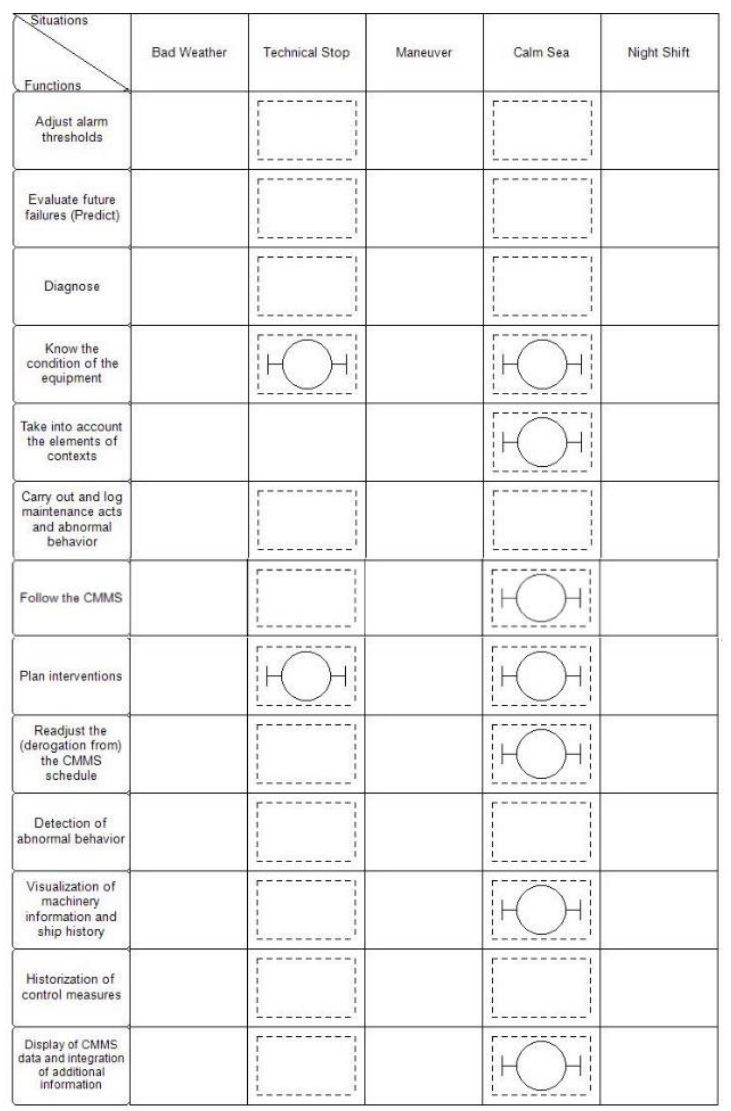

Figure 3: CAT for planning activity 


\section{Lö̈ck Simon, Clément Guérin, Philippe Rauffet and Julie Lassalle}

\section{Discussion}

The three functional purposes of the maintenance are "maintaining the authorisation", "keeping the crew and the passengers safe" and "maintaining the vessel in an optimal condition". Actually, to fill this purpose the chief engineer will try to follow the CMMS strictly. The re-planning doesn't really exist. If an operation can't be done, it will impact the future days of work and might create a work overload. On rare occasions the chief engineer will report maintenance when he sees an interesting opportunity like a dry dock. This dry dock happens every 5 years in the merchant navy and the chief engineer has nothing but his experience to judge the possibility of this report. With predictive maintenance, replanning will become a key new function making it easier and safer. To avoid a work overload, the chief engineer will be able to re-plan some operations and adjust the calendar to the open possibility. To adjust this calendar, the chief engineer will need some information from diverse sources (material information, crew information, equipment information, planning information etc.).

In a predictive maintenance system, the replanning activity will be supported by two tactic functions. The first one is the supervision activity. It will give information about the possibility to re-plan maintenance (to advance or to report) by knowing the past, the present and the future state of the equipment. The state of the equipment will guide the re-planning decision. With predictive maintenance the supervision activity can be more complex because of a higher number of data than a classic supervision. In a classic supervision, numeric values are the most used. There is a temporality in predictive maintenance, so the number of data is higher and those data need to be represented with a line graph. Furthermore, the operator might need an explanation to understand them. Since some of the data are historized, it is necessary to have the acquisition context.

The second one is the activity of gathering information from contextual elements. There are many contextual elements that need to be taken into account: the availability of the crew, the weather, the vessel schedule (technical stop, long period at sea, mooring, etc.), the other maintenance operations and the stocks. The contextual elements will help the chief to identify the appropriate time for the replanning.

The chief engineer will aggregate the data from the supervision and the contextual element to improve his environment knowledge. On one hand the state of the equipment, and its limits, and on the other hand the possible good time to plan the new maintenance operation. At the end, it is still the chief engineer who decides to re-plan or not, but the predictive maintenance will offer opportunities, and a higher flexibility.
As we have seen, the representation of the numerous data in predictive maintenance (supervision) might be problematic for the operator. Big data is known as a problem that needs to be treated (Woods, Patterson \& Roth, 2002). Big data is a key for predictive maintenance and the future user needs their utilization. Also, there are plenty of different types of contextual elements that need to be presented to the user. Another aspect is that predictive maintenance is using algorithms. For the user, it can be seen as a black box and there is a risk associated with the use (Parasuraman \& Riley, 1997). To help and improve the cooperation between those algorithms and the chief engineer the interface will serve as a broker agent. A reflection needs to be carried out on those interfaces, specifically on the information's presentation (Thoben, Wiesner \& Wuest, 2017). Those observations lead to the need of an interface that can represent information in a usable, understandable and effortless way.

One solution to solve those problems is to design ecological interface. Multiple domains, like military or healthcare domains, are already using ecological interfaces (Mcllroy \& Stanton, 2015). Sea domains related, like submarines, are also using ecological interfaces (Fay, Roberts \& Stanton, 2020; Fay, Stanton \& Roberts, 2017, Judas \& al, 2012). Those interfaces improve the situation awareness (Van Dam, Mulder \& Van Paasen, 2008), reduce the cognitive load (Nielsen, Goodrich \& Ricks, 2007; Schewe \& Volrath, 2020) and more generally improve the performance (Bennett \& Flach, 2019). Ecological interfaces are also useful for handling unexpected events (Burns \& Hajdukiewicz, 2004; Bennet, 2017) and for a supervision activity (Naikar, 2017). Maintenance activities tackle both unexpected events (e.g., when an equipment broke) and supervision activity (e.g., monitoring the alarm center in a vessel).

The analysis from the CWA helps to identify the main information needed for the key function (supervision and re-planning) and guide the design of the interface. The interface will improve the situation awareness and help the user to make decisions. For example, the WDA highlights the need to know the context for a re-planning. The interface will need to represent those contexts in a calendar or in a Gantt Chart if we want to create an ecological interface. Displaying this information would allow the chief engineer to make relevant decision, by knowing environmental constraints. For the supervision activity, the WDA has highlighted the need to have access to the manufacturer's information. Therefore, the representation of the data will have the limitations of the equipment. This representation will allow the user to know the maximum or minimum pressure that can endure an equipment with a limited effort. The SOCA-CAT shows that the supervision activity requires to have access to the contextual information like the 


\section{Lö̈ck Simon, Clément Guérin, Philippe Rauffet and Julie Lassalle}

weather. This will help the user to understand the line graph and the explanation of some abnormal behaviors.

Finally, the SOCA-CAT has allowed us to identify the possibility of separate interfaces for different user classes. A technique that has already been used in adaptive interface (Akiki, Bandara \& $\mathrm{Yu}, 2013)$. For example, the chief engineer may need to have access to all functions and information of the entire system, when the electric team officer will only need to analyze electrical system's information.

\section{Conclusion}

The objective of this paper was to identify how the introduction of a predictive maintenance system in a maritime environment impacts human cognitive activities. The Cognitive Work Analysis has allowed us to understand those impacts and gave us design advice for an ecological interface. All teams who want to implement can refer to this analysis to understand the need of the chief engineer for good use of predictive maintenance. Having access to contextual element for the re-planification and the supervisory tasks are crucial to ensure a good implantation of predictive maintenance. The other crucial information for the chief engineer is to have access to a comparative with the CMMS because it will always be the baseline of the maintenance calendar

This paper highlights the fact that predictive maintenance in the maritime context is peculiar because the vessel can be considered as a "moving industry". This "moving industry" will have to consider more contextual and environmental data than a classic industry and it will create two major difficulties. The first one is related to the interface that the operators will use. Those data will complicate the comprehension of the system by the operator. There is a need to focus on the humanmachine interaction and the allocated interface to solve this problem. As previously explain, an ecological interface could be a solution. The second one concerns the algorithm. It will need to take into account those multiple extern factors. Those many changing extern conditions have a big incidence on the components, and the predictive algorithm will need to take them into account.

Another peculiarity of predictive maintenance in maritime domain is the legislation. Obtaining a navigation authorization is very regulated and strict. The implemention of predictive maintenance needs to consider an agreement from the manufacturer (to keep the assurance) and from the classification society (to keep the right to navigate).

Predictive maintenance is new for the maritime domain. Nowadays, the most advance maintenance used is conditional maintenance (for petrol platforms for example). With this implementation, new activities arise like re-planning the intervention based on projection. There are a lot of implications because it will lead to an update of the current formation and the current chief engineer might need formation in order to change it habits.

Predictive maintenance is one of the applications of technological pillars of Industry 4.0. The introduction of technology requires a better understanding of human-machine cooperation mechanisms because humans and autonomous agents pool their skills in order to "feed each other and help each other" (Fantini, Pinzone, \& Taisch, 2018) for the emergence of a joint cognitive system (Rauffet et al., 2018). For these reasons, the humanmachine symbiosis must be based on rules for adapting functions and interaction conditions (Romero, Wuest, Stahre and Gorecky, 2017 ; Steijn, Oosterhout, Willemsen \& Jansen, 2020). The CWA method has already been used in research on humanmachine cooperation for Industry 4.0 (Guerin et al., 2019; Pacaux-Lemoine et al., 2021) but further studies are needed. These future works will improve our understanding of operator 4.0 or analytical operator, in cognitive interaction with technological systems (Romero et al., 2016). In this perspective, the maintenance operator 4.0 will be able to make relevant decisions assisted by systems with higher ability to deal with many data.

\section{Acknowledgement}

The research presented in this paper is carried out in the context of the SEANATIC Project (N²082C0023). This project is supported by the Future Investments Program (PIA) operated by ADEME (the French Environment and Energy Management Agency).

Thank you to Paul Salmon for the authorization of using the CWA tool: Software tools. (2015, novembre 16). Centre for Human Factors and Sociotechnical Systems. https://hf-sts.com/software-tools/

\section{References}

Akiki, Pierre, Arosha Bandara, et Yijun Yu. 2013. RBUIS: Simplifying Enterprise Application User Interfaces through Engineering Role-Based Adaptive Behavior. EICS 2013 - Proceedings of the ACM SIGCHI Symposium on Engineering Interactive Computing Systems. https://doi.org/10.1145/2494603.2480297.

Bennett, Kevin B. 2017. « Ecological Interface Design and System Safety: One Facet of Rasmussen's Legacy ». Applied Ergonomics, The Legacy of Jens Rasmussen, 59 (mars): $625-36$. https://doi.org/10.1016/j.apergo.2015.08.001.

Bennett, Kevin B., et John Flach. 2019. «Ecological Interface Design: Thirty-Plus Years of Refinement, Progress, and Potential ». Human Factors 61 (4): $513-25$. https://doi.org/10.1177/0018720819835990.

Burns, Catherine M., et John Hajdukiewicz. 2004. Ecological Interface Design. CRC Press.

Culot, Giovanna, Guido Nassimbeni, Guido Orzes, et Marco Sartor. 2020. «Behind the Definition of Industry 4.0: Analysis and Open Questions ». International Journal of Production Economics 226 
7 Loïck Simon, Clément Guérin, Philippe Rauffet and Julie Lassalle

(août): 107617. https://doi.org/10.1016/j.ijpe.2020.107617.

Eruguz, Ayse Sena, Tarkan Tan, et Geert-Jan van Houtum. 2017. «A Survey of Maintenance and Service Logistics Management: Classification and Research Agenda from a Maritime Sector Perspective ». Computers \& Operations Research 85 (septembre): 184-205. https://doi.org/10.1016/j.cor.2017.03.003.

Fantini, Paola, Marta Pinzone, et Marco Taisch. 2020. «Placing the operator at the centre of Industry 4.0 design: Modelling and assessing human activities within cyber-physical systems ». Computers \& Industrial Engineering 139: 105058.

Fay, Daniel, Aaron PJ Robers, et Neville A Stanton. 2020. «Designing Future Submarine Control Room HMIs ». Contemporary Ergonomics and Human Factors, 5.

Fay, Daniel, Neville A Stanton, et Aaron Roberts. 2017. «Designing New Interfaces for Submarines: From Cognitive Work Analysis to Ecological Interface Design ». In Advances in Human Aspects of Transportation, édité par Neville A. Stanton, Steven Landry, Giuseppe Di Bucchianico, et Andrea Vallicelli, 484:413-25. Advances in Intelligent Systems and Computing. Cham: Springer International Publishing. https://doi.org/10.1007/978-3-319-41682-3_35.

Goossens, Adriaan J. M., et Rob J. I. Basten. 2015. « Exploring Maintenance Policy Selection Using the Analytic Hierarchy Process; An Application for Naval Ships ». Reliability Engineering \& System Safety $\quad 142 \quad$ (octobre): $31-41$. https://doi.org/10.1016/j.ress.2015.04.014.

Guerin, C., Rauffet, P., Chauvin, C., Martin, E. (2019). Toward production operator 4.0: modelling HumanMachine Cooperation in Industry 4.0 with Cognitive Work Analysis. IFAC Human-Machine System, Sept, Tallinn, Estonia.

Holman, Matt, Guy Walker, Terry Lansdown, Paul Salmon, Gemma Read, et Neville Stanton. 2020. «The Binary-Based Model (BBM) for Improved Human Factors Method Selection ». Human Factors, juin, $\quad 0018720820926875$. https://doi.org/10.1177/0018720820926875.

Jenkins, D. P., N. A. Stanton, P. M. Salmon, G. H. Walker, et M. S. Young. 2008. «Using cognitive work analysis to explore activity allocation within military domains ». Ergonomics 51 (6): 798-815. https://doi.org/10.1080/00140130801915246.

Judas, Samantha, Philippe Rauffet, Gaël Morel, Christine Chauvin, Pascal Berruet, et Norbert Toumelin. 2012. «Evaluation de l'apport d'une interface écologique appliquée au pilotage de sous-marin ». In Proceedings of the 2012 Conference on Ergonomie et Interaction homme-machine, 189-92. Ergo'IHM '12. New York, NY, USA: Association for Computing Machinery. https://doi.org/10.1145/2652574.2653435.

Lazakis, Iraklis, et Aykut Ölçer. 2016. «Selection of the Best Maintenance Approach in the Maritime Industry under Fuzzy Multiple Attributive Group Decision-Making Environment ». Proceedings of the Institution of Mechanical Engineers, Part M: Journal of Engineering for the Maritime $\begin{array}{lccc}\text { Environment } & 230 & \text { (2): } & \text { 297-309. }\end{array}$ https://doi.org/10.1177/1475090215569819.
Longo, Francesco, Letizia Nicoletti, et Antonio Padovano. 2017. «Smart operators in industry 4.0: A humancentered approach to enhance operators' capabilities and competencies within the new smart factory context ». Computers \& industrial engineering 113: 144-59.

«MAN B\&W 5L90MC VLCC L11-V - KONGSBERG DIGITAL ». s. d. Consulté le 18 décembre 2020. https://www.kongsberg.com/fr/digital/models-andexamples/k-sim-engine-models/man-bw-5190mcvlcc/.

McIlroy, Rich C., et Neville Stanton. 2015. «Ecological Interface Design Two Decades On: Whatever Happened to the SRK Taxonomy?» IEEE Transactions on Human-Machine Systems 45 (avril): https://doi.org/10.1109/THMS.2014.2369372.

Naikar, Neelam. 2017. «Cognitive Work Analysis: An Influential Legacy Extending beyond Human Factors and Engineering ». Applied Ergonomics, The Legacy of Jens Rasmussen, 59 (mars): 528-40. https://doi.org/10.1016/j.apergo.2016.06.001.

«NF EN 13306 - Janvier 2018 ». s. d. Consulté le 18 décembre 2020. https://www.boutique.afnor.org/norme/nf-en13306/maintenance-terminologie-de-lamaintenance/article/828621/fa185755.

Nielsen, Curtis W., Michael A. Goodrich, et Robert W. Ricks. 2007. « Ecological Interfaces for Improving Mobile Robot Teleoperation ». IEEE Transactions $\begin{array}{llll}\text { on } & \text { Robotics } & 23 & \text { (5): }\end{array}$ https://doi.org/10.1109/TRO.2007.907479.

Pacaux-Lemoine, M.P., Berdal, Q., Guerin, C., Rauffet, P., Chauvin C., \& Trentesaux, D. (2021). Designing Human-Systems Cooperation in Industry 4.0 with Cognitive Work Analysis: a first evaluation. Cognition, Technology \& Work.

Parasuraman, Raja, et Victor Riley. 1997. « Humans and Automation: Use, Misuse, Disuse, Abuse ». Human Factors: The Journal of the Human Factors and Ergonomics Society 39 (2): 230-53. https://doi.org/10.1518/001872097778543886.

Rasmussen, J. 1986. «Information Processing and Human-Machine Interaction». An approach to cognitive https://ci.nii.ac.jp/naid/10004210302/.

Rauffet, Philippe, Christine Chauvin, Gael Morel, et Pascal Berruet. 2015. «Designing sociotechnical systems: a CWA-based method for dynamic function allocation ». In Proceedings of the European Conference on Cognitive Ergonomics 2015, 1-8. ECCE '15. New York, NY, USA: Association for Computing Machinery. https://doi.org/10.1145/2788412.2788433.

Rauffet, P., Guerin, C., Chauvin, C., \& Martin, E. (2018). Contribution of Industry 4.0 to the emergence of a joint cognitive and physical production system. In Human Factors and Ergonomics Society European chapter. Berlin, Germany.

Raymond, Camille, Daniel Prun, et Julien Cegarra. 2016. «Associer l'ingénierie système et le Cognitive Work Analysis pour soutenir l'intégration HommeSystème ». In, https://hal-enac.archivesouvertes.fr/hal-01626011.

Romero, David, Johan Stahre, Thorsten Wuest, Ovidiu Noran, Peter Bernus, Åsa Fast-Berglund, et Dominic Gorecky. 2016. « Towards an operator 4.0 typology: 
8 Lö̈ck Simon, Clément Guérin, Philippe Rauffet and Julie Lassalle

a human-centric perspective on the fourth industrial revolution technologies ». In proceedings of the international conference on computers and industrial engineering (CIE46), Tianjin, China, 2931.

Romero, David, Thorsten Wuest, Johan Stahre, et Dominic Gorecky. 2017. «Social Factory Architecture: Social Networking Services and Production Scenarios Through the Social Internet of Things, Services and People for the Social Operator $4.0 »$. In Advances in Production Management Systems. The Path to Intelligent, Collaborative and Sustainable Manufacturing, édité par Hermann Lödding, Ralph Riedel, Klaus-Dieter Thoben, Gregor von Cieminski, et Dimitris Kiritsis, 265-73. IFIP Advances in Information and Communication Technology. Cham: Springer International Publishing. https://doi.org/10.1007/978-3-31966923-6_31.

Schewe, F., et M. Vollrath. 2020. « Ecological Interface Design Effectively Reduces Cognitive Workload The Example of HMIs for Speed Control ». Transportation Research Part F: Traffic Psychology and Behaviour 72 (juillet): 155-70. https://doi.org/10.1016/j.trf.2020.05.009.

Steijn, Wouter. M.P., Jeroen van Oosterhout, Joeri Willemsen, et Anne Jansen. 2020. « Modelling Human-Robot Interaction to Optimize Their Safety, Sustainability and Efficiency: Identifying Relevant Characteristics ». In Proceedings of the 30th European Safety and Reliability Conference and 15th Probabilistic Safety Assessment and Management Conference, 2571-77. Research Publishing Services. https://doi.org/10.3850/978981-14-8593-0_4059-cd.

Thoben, Klaus-Dieter, Stefan Wiesner, et Thorsten Wuest. 2017. " "Industrie 4.0" and Smart Manufacturing A Review of Research Issues and Application Examples ». International Journal of Automation Technology $11 \quad$ (1): $4-16$. https://doi.org/10.20965/ijat.2017.p0004.

Tinga, T., W. W. Tiddens, F. Amoiralis, et M. Politis. 2017. "Predictive Maintenance of Maritime Systems: Models and Challenges ». In Safety \& Reliability - Theory and Applications: Proceedings of the 27th European Safety and Reliability Conference (ESREL 2017), 421-29. Taylor \& Francis. https://doi.org/10.1201/978131521046956.

Torenvliet, Gerard, Greg Jamieson, et Luc Cournoyer. 2006. «Functional Modelling, Scenario Development, and Options Analysis to Support Optimized Crewing for Damage Control », 94.

Turan, O., A. İ. Ölçer, I. Lazakis, P. Rigo, et J. D. Caprace. 2009. «Maintenance/Repair and ProductionOriented Life Cycle Cost/Earning Model for Ship Structural Optimisation during Conceptual Design Stage ». Ships and Offshore Structures 4 (2): $107-$ 25. https://doi.org/10.1080/17445300802564220.

Van Dam, Stijn B. J., Max Mulder, et M. M. van Paassen. 2008. «Ecological Interface Design of a Tactical Airborne Separation Assistance Tool ». IEEE Transactions on Systems, Man, and Cybernetics Part A: Systems and Humans 38 (6): 1221-33. https://doi.org/10.1109/TSMCA.2008.2001069.

Walker, Guy H., Neville A. Stanton, Paul M. Salmon, Daniel P. Jenkins, et Laura Rafferty. 2010.
«Translating concepts of complexity to the field of ergonomics ». Ergonomics 53 (10): 1175-86. https://doi.org/10.1080/00140139.2010.513453.

Wan, Jiafu, Shenglong Tang, Di Li, Shiyong Wang, Chengliang Liu, Haider Abbas, et Athanasios V. Vasilakos. 2017. «A manufacturing big data solution for active preventive maintenance ». IEEE Transactions on Industrial Informatics 13 (4): 203947.

Woods, David, Emily Patterson, et Emilie Roth. 2002. «Can We Ever Escape from Data Overload? A Cognitive Systems Diagnosis ». Cognition, Technology \& Work 4 (avril): 22-36. https://doi.org/10.1007/s101110200002.

Wuest, Thorsten, Christopher Irgens, et Klaus-Dieter Thoben. 2014. «An approach to monitoring quality in manufacturing using supervised machine learning on product state data ». Journal of Intelligent Manufacturing 25 (5): 1167-80.

Yan, Jihong, Yue Meng, Lei Lu, et Lin Li. 2017. «Industrial Big Data in an Industry 4.0 Environment: Challenges, Schemes, and Applications for Predictive Maintenance ». IEEE Access 5: 23484-91. https://doi.org/10.1109/ACCESS.2017.2765544.

Yang, Chunsheng, Yubin Yang, Xiaohui Yang, et Qiangqiang Cheng. 2020. " Machine LearningEnabled Modeling Approach for Predictive Maintenance Decision-Making Support ». In Proceedings of the 30th European Safety and Reliability Conference and 15th Probabilistic Safety Assessment and Management Conference, 3407-14. Research Publishing Services. https://doi.org/10.3850/978-981-14-8593-0_4043cd. 